\title{
The emulsification characteristics research of produced fluid in weak base alkaline-sufactant-polymer flooding
}

\author{
Di Wang ${ }^{1, a}$, Yujia Jiao ${ }^{2, \text { b }}$
}

1School of Petrochemical Engineering, Northeast Petroleum University, Daqing 166318, China;

2School of Petrochemical Engineering, Northeast Petroleum University, Daqing 166318, China;

a286788704@qq.com, b125812800@qq.com

Keywords: Weak base alkaline-surfactant-polymer, Produced fluid, emulsify, IFT

\begin{abstract}
The emulsifying characteristics research of the produced liquid in weak base alkaline-surfactant-polymer lay the theoretical foundation for the process ofoil-water separation and the choice of operating parameters, this paper mainly researchs the degree of emulsification of produced fluid, the properties of electrostatic double layer and interfacial tension. Studies have shown that the emulsified state of produced fluid is complex, it shows the coexistence of multiple emulsion, the average granul diametre of internal phase in emulsion fluid is $4.48-7 \mathrm{um}$, and the thickness of boundary mask increases until the maximum thickness reachs to $2.5 \mathrm{um} \sim 3.75 \mathrm{um}$; the Zeta potential in diffuse electric double layer of charged ions is between $-30 \mathrm{mV} \sim-50 \mathrm{mV}$; the boundary mask of produced liquidis always between $0.01 \sim 1 \mathrm{mN} / \mathrm{m}$, less than the oil/water interfacial tension of the produced liquid in strong base alkaline-surfactant-polymer.The stability of emulsion is good, and not conducive to oil-water separation.

Strong base three compound combination flooding is mostly used in Daqing oil field [1-5]. The existence of $\mathrm{NaOH}$ causes scaling and blocking of oil layer [6-11] and the scaling and corrosion of oil well holddown, ground gathering pipeline and process equipment in production. Moreover, the produced liquid is difficult to be processed and the cost is high $[12,13]$. In order to avoid these adverse effect, substitution of $\mathrm{NaOH}$, namely weak base ASP flooding, with $\mathrm{Na} 2 \mathrm{CO} 3$ or $\mathrm{NaHCO} 3$ has been applied in Daqing oil field at present [14-17]. However, there is no quantitative study on interfacial characteristic and emulsification of produced liquid of ASP flooding pilot block. The paper makes emulsification characteristic research on produced liquid based on some weak base ASP flooding pilot block. It can provide lay theoretical basis for the selection of oil-water separation technology of weak base ASP flooding produced liquid, the optimization of equipment structure, processing temperature and dosing concentration and facilitate the application of weak base ASP flooding in the oil field.
\end{abstract}

\section{Research on emulsification of produced liquid}

Make analysis of actual oil well sample by using particle image processor PIP9.0 and make comparison with water flooding produced liquid. some of analysis result is shown in Table 1.

Table 1 Emulsification Comparison of water flooding and weak base ternary flooding produced liquid

\begin{tabular}{|c|c|c|c|c|c|}
\hline \multirow{2}{*}{ Produced liquid } & well & particle size range & $\begin{array}{c}\text { Mean } \\
\text { volume } \\
\text { diameter }\end{array}$ & $\begin{array}{c}\text { Average } \\
\text { quantity } \\
\text { particle size }\end{array}$ & $\begin{array}{c}\text { Compute specific } \\
\text { surface area }\end{array}$ \\
\hline \multirow{2}{*}{$\begin{array}{c}\text { Water flooding } \\
\text { produced liquid }\end{array}$} & Glycosyl 73-90 & $2.85-72.10$ & $29.39 \mathrm{um}$ & $8.07 \mathrm{um}$ & $0.67 \mathrm{~m} 2 / \mathrm{cm} 3$ \\
\cline { 2 - 6 } & Glycosyl 70-inclined 892 & $2.85-92.44$ & $33.47 \mathrm{um}$ & $8.18 \mathrm{um}$ & $0.65 \mathrm{~m} 2 / \mathrm{cm} 3$ \\
\hline $\begin{array}{c}\text { Ternary } \\
\text { produced liquid }\end{array}$ & $\begin{array}{c}\text { South 4-butane 20-inclined } \\
\text { P038 }\end{array}$ & $2.85-43.86$ & $13.54 \mathrm{um}$ & $5.43 \mathrm{um}$ & $0.490 \mathrm{~m} 2 / \mathrm{cm}^{2}$ \\
\cline { 2 - 6 } & N4- butane 30-P038 & $2.85-43.86$ & $14.33 \mathrm{um}$ & $4.48 \mathrm{um}$ & $0.521 \mathrm{~m}^{2} / \mathrm{cm}^{3}$ \\
\hline
\end{tabular}

Particle size distribution and accumulative particle size distribution is shown in Figure 1 to 4. 

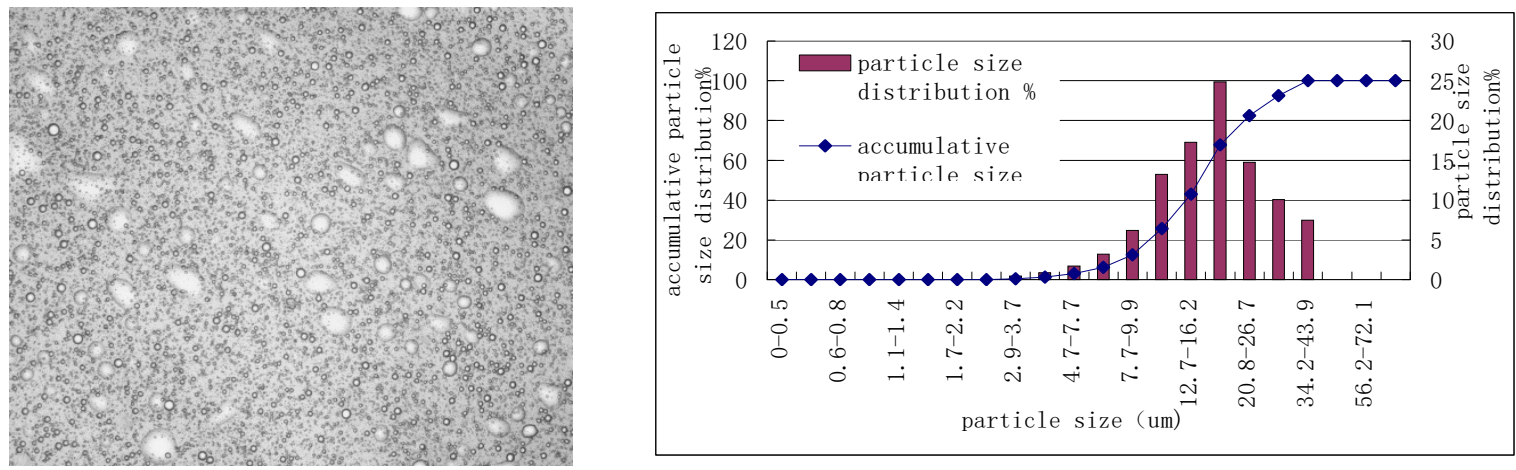

Figure 1 Emulsification of south 4- butane 20- inclined P038 well

Figure 2 emulsion particle size and accumulative particle size distribution of south 4- butane 20inclined P038 well
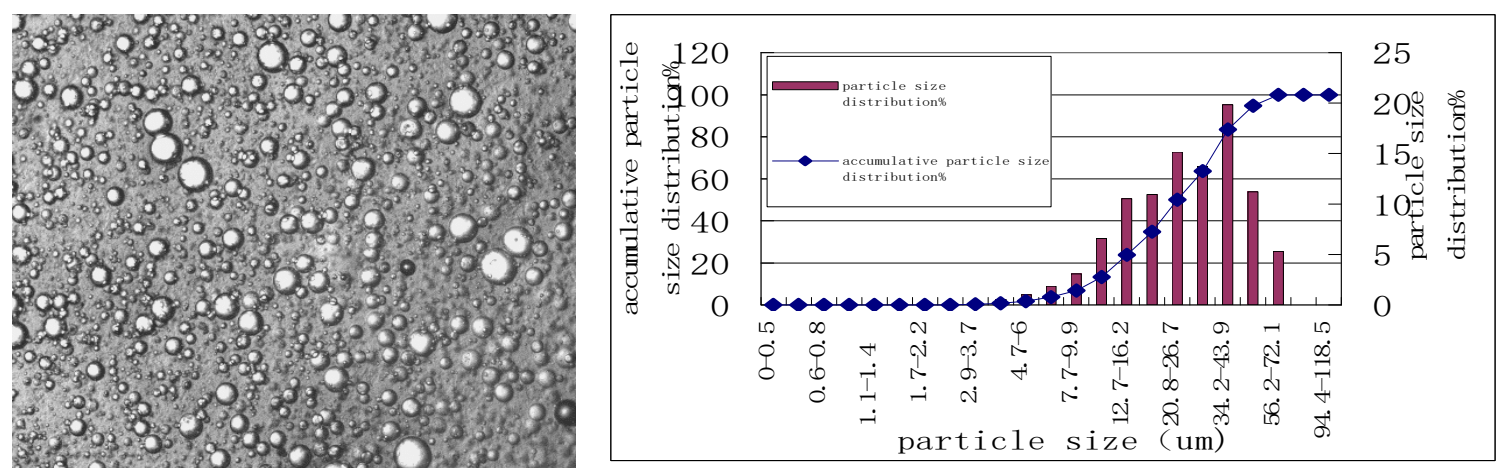

Figure 3 Water flooding produced liquid emulsification of glycosyl 70- inclined 892 Figure 4 Emulsion particle size and accumulative particle size distribution of glycosyl 70- inclined 892 well

Emulsion of water flooding produced liquid is $\mathrm{W} / \mathrm{O}$ emulsion and weak base ternary flooding produced liquid. Because it contains chemical agent, the emulsion state of produced liquid is more complicated. Except $\mathrm{W} / \mathrm{O}$ and $\mathrm{O} / \mathrm{W}$, it includes $\mathrm{O} / \mathrm{W} / \mathrm{W}$ and appears multiple emulsions. Mean particle size of internal phase of chemical flooding produced liquid emulsion is 4.48-5.5um, while particle size of water flooding produced liquid is $8.07-8.18 \mathrm{um}$, and the thickness of interfacial film increases. The minimal thickness reaches $2.5 \mathrm{um} \sim 3.75 \mathrm{um}$ and the emulsion have good stability and is bad for oil-water separation.

\section{Double electrode layer potential detection of produced liquid}

Some block of Daqing oil field is weak base ASP flooding. According to the predicted value of chemical agent content in produced liquid (the maximal predictor is $1000 \mathrm{mg} / \mathrm{L}$; the highest predictor of surface active agent is $130 \mathrm{mg} / \mathrm{L}$; the highest predictor of polymer is $1300 \mathrm{mg} / \mathrm{L}$ ), simulate to allocate different chemical agent content of emulsion in room. Figure 5 is the measured result that content of chemical agent is $100 \%, 80 \%, 60 \%, 30 \%$ and $20 \%$ of the highest predictor and Zeta potential of strong base flooding and water flooding produced liquid. Figure 6 is the Zate potential measured result of actual produced liquid of oil well at different time. According to the measured result, Zeta potential value of diffused double layer strong base ASP flooding produced liquid charged ion is $-69.26 \mathrm{mV}$, absolute vlue of strong base Zeta is greater than Zeta potential value of weak base ASP flooding produced liquid, while Zeta potential value of common water flooding produced liquid is $-14.78 \mathrm{mV}$. Zeta potential value of diffused double layer strong weak ASP flooding produced liquid charged ion is $-30 \mathrm{mV} \sim-50 \mathrm{mV}$. The higher the chemical agent content of produced liquid is, the greater the absolute value of ternary produced liquid potential is; the higher the Zeta potential absolute value is, the more stable the emulsion is and it's bad for dehydration. The difficulty of weak base ternary flooding produced liquid is smaller than that of strong base ternary flooding produced liquid. 

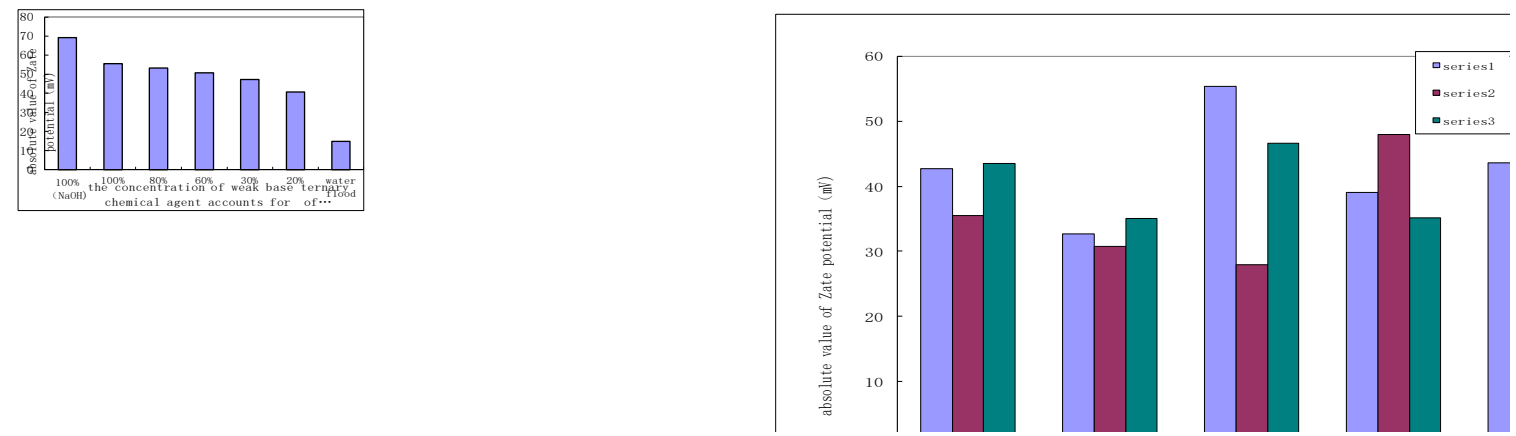

Figure 5 Zeta potential value of different chemical agent content that simulates produced liquid Figure 6 Zeta potential value of oil well produced liquid at different times

\section{Research on interfacial tension of produced liquid}

Oil-water interfacial tension is the tension produced by molecule in two-phase interface area receiving asymmetric molecular attraction $[21,22]$. The interfacial tension affects the stability of emulsion directly, weak base ternary flooding produced liquid and adsorption of alkali, active agent, and polymer on oil-water interface may result in the decreasing of interfacial tension. The smaller the interfacial tension is, the more stable the emulsion is, which is bad for dehydration of crude oil. Table 2 is the measured value of oil-water interfacial tension of simulation produced liquid under different concentration of chemical agent. Figure 7 is interfacial tension measured value of 6 sampling wells at different time

Table 2 Measured value of oil-water interfacial tension of simulation produced liquid under different concentration of chemical agent

\begin{tabular}{|c|c|c|c|c|c|c|}
\hline \multirow{2}{*}{ No. } & \multirow{2}{*}{$\begin{array}{c}\text { temperature } \\
\left({ }^{\circ} \mathrm{C}\right)\end{array}$} & \multirow{2}{*}{$\begin{array}{c}\text { rotation } \\
\text { speed } \\
\mathrm{r} / \mathrm{min}\end{array}$} & $\begin{array}{c}\left(\mathrm{Na}_{2} \mathrm{CO}_{3}\right) \text { alkali } \\
\mathrm{ppm}\end{array}$ & $\begin{array}{c}\text { active agent } \\
\text { ppm }\end{array}$ & \multirow{2}{*}{ polymer ppm } & \multirow{2}{*}{$\begin{array}{c}\text { interfacial tension } \\
\mathrm{mN} / \mathrm{m}\end{array}$} \\
\hline 1 & 50 & 5000 & \multicolumn{2}{|c|}{ Simulated water } \\
\hline 2 & 50 & 5000 & 1000 & 130 & 1300 & 23 \\
\hline 3 & 50 & 5000 & 800 & 100 & 1000 & 0.01 \\
\hline 4 & 50 & 5000 & 600 & 78 & 780 & 0.236 \\
\hline 5 & 50 & 5000 & 300 & 40 & 400 & 0.255 \\
\hline 6 & 50 & 5000 & 200 & 25 & 250 & 0.402 \\
\hline 7 & 50 & 5000 & $1000(\mathrm{NaOH})$ & 130 & 1300 & 0.173 \\
\hline
\end{tabular}

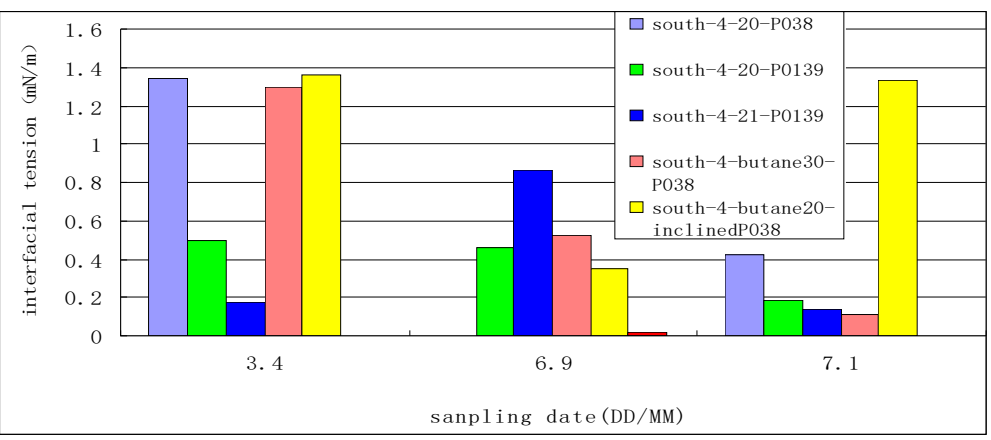

Figure 7 interfacial tension measured value of sampling well

From Table 2, it can be seen that oil-water interfacial tension of ternary flooding produced liquid of strong base $\mathrm{NaOH}$ and weak base $\mathrm{NaOH}$ with the same concentration is different. The oil-water tension of strong base ternary flooding produced liquid is $0.173 \mathrm{mN} / \mathrm{m}$, while oil-water tension of weak base ternary flooding produced liquid is $1.656 \mathrm{mN} / \mathrm{m}$. It indicates that the processing of weak base ternary produced liquid is less difficult than that of strong base.

The general interfacial tension of weak base ternary produced liquid is $0.01 \sim 1 \mathrm{mN} / \mathrm{m}$. Of these, most of them is $0.1-1 \mathrm{mN} / \mathrm{m}$ and some of them is $1-10 \mathrm{mN} / \mathrm{m}$, while that of common water is $23 \mathrm{mN} / \mathrm{m}$; chemical agent content increases, interfacial tension decreases and active agent has greatest influence on interfacial tension. The lower the interfacial tension is, the more stable the emulsion is, which is bad for dehydration of crude oil. 


\section{Conclusion}

Through research on emulsion of weak base ternary produced liquid and potential and interfacial tension of double electro layer, weak base ternary produced liquid has the following emulsion characteristics:

Owing to containing chemical agent, weak base ternary produced liquid is more complicated. Except containing $\mathrm{W} / \mathrm{O}$ and $\mathrm{O} / \mathrm{W}$, it also contains $\mathrm{O} / \mathrm{W} / \mathrm{O}$ and appears the coexistence of multiple emulsions.

Average internal phase particle size of chemical flooding produced liquid emulsion is 4.48-5.5um, while water flooding produced liquid particle size is $8.07-8.18 \mathrm{um}$, and the thickness of interfacial film increases. The maximal thickness reaches $2.5 \mathrm{um} \sim 3.75 \mathrm{um}$ and emulsion has good stability, which is bad for oil-water separation.

Zeta potential value of diffused double layer strong weak ASP flooding produced liquid charged ion is $-30 \mathrm{mV} \sim-50 \mathrm{mV}$, which is smaller than that of strong base ternary produced liquid with the same concentration. The higher the chemical agent content of produced liquid is, the greater the absolute value of ternary produced liquid potential is; the higher the absolute value of Zeta potential is, the more stable the emulsion is;

The oil-water interfacial tension of strong base ternary flooding produced liquid with the same concentration is greater than that of weak base ternary flooding produced liquid; the interfacial tension of strong base ternary produced liquid is usually $0.01 \sim 1 \mathrm{mN} / \mathrm{m}$. Most of them are $0.1-1 \mathrm{mN} / \mathrm{m}$ and some of them are $1-10 \mathrm{mN} / \mathrm{m}$.

The processing of weak base ternary produced liquid is less difficult than that of strong base.

\section{Reference}

[1]Wu Kaikai Liang Guangchuan Ma peihong,etc. Analysis of influencing factors on demulsification of heavy oil emulsion breaking polyether[J]. Natural Gas And Oil, 2010,02:12-14.

[2]Guo Chunping,Zhu huifeng,Wang Haoyu,ect.Characteristics of Interface Tension and Oil Displacement with ASP Floodingp[J]. Natural Gas And Oil,2010,02:12-14.

[3]Gong Qiuhong,Wang Hongsong,Sun Xiang,etc.Viscosity Reduction of Heavy Oil Mixed with Sewage in Bamianhe Oilfield[J]. Natural Gas And Oil, 2011,05:15-17.

[4]Dong Zhengliang,Chen Dajun,Hou Xulin,etc.Analysis on Gas Well Dirt in Longgang Reef Reservoir and Study on its Blockage Mechanism[J]. Natural Gas And Oil, 2011,05:15-17.

[5]Ouyang Xiangnan,Tang Shanfa,Hu Xiaodong,etc.Study on Dynamic Interfacial Tension between Gemini Surfactant and Crude Oil.[J]. Natural Gas And Oil, 2012,02:71-73.

[6]Pan Weiqing,Zhong Xinmin,Wu Jin,etc. Analysis of fouling characteristics experiment of crude oil pipeline steel glass[J]. Natural Gas And Oil, 2015,01:16-19.

[7]Liu Wenjie ,Studies on Oil-Water Separation Property of ASP Flooding Produced Liquid [D]. Daqing petroleum institute, 2007.

[8]Shen Minghuan.Demulsification of Polymer Flooding Produced Fluids in Bohai Oilfield.[D]. Harbin Engineering University,2007.

[9]Zhou Liping. Research on Chemical Demulsifying of Cruid Oil Emulsions from ASP Flooding [D]. Daqing petroleum institute,2006. 